\title{
Correction to: The impact of low education and poor health on unemployment varies by work life stage
}

\author{
Sander K. R. van Zon ${ }^{1} \cdot$ Sijmen A. Reijneveld ${ }^{1} \cdot$ Carlos F. Mendes de Leon ${ }^{2} \cdot$ Ute Bültmann $^{1}$
}

Published online: 11 June 2018

(C) Swiss School of Public Health (SSPH+) 2018

\section{Correction to: Int J Public Health (2017) 62:997-1006 https://doi.org/10.1007/s00038-017-0972-7}

During the calculation of the physical component score and the mental component score, the score of the RAND 1 was erroneously coded in the opposite direction. After correcting this mistake, the interaction between low education and poor physical health on unemployment in early work life becomes statistically significant. In addition, other RERIs and odds ratios change somewhat in magnitude but remain fairly similar.

In the abstract, the result section should read as: Results: Interactions of low education and poor mental health were found in early [RERI: 2.13 ; 95\% confidence interval (CI) $0.61,3.64]$, mid $(1.41 ; 0.61,2.20)$ and late $(0.58 ; 0.04$, 1.11) work life. Interaction between low education and poor physical health was found in early (RERI: 1.66; 95\% CI $0.26,3.07)$ and mid-work life $(1.25 ; 0.56,1.93)$.

In the result section, the last sentence of the first paragraph should read as: The prevalence of people with poor physical health increased stepwise by work life stage from $20.0 \%$ in early to $29.5 \%$ in late work life. The opposite was observed for mental health (27.2-20.3\%).

The original article can be found online at https:// doi.org/10.1007/s00038-017-0972-7.

Electronic supplementary material The online version of this article (https://doi.org/10.1007/s00038-018-1123-5) contains supplementary material, which is available to authorized users.

Sander K. R. van Zon

s.k.r.van.zon@umcg.nl

1 Department of Health Sciences, Community and Occupational Medicine, University Medical Center Groningen, University of Groningen, Groningen, The Netherlands

2 Center for Social Epidemiology and Population Health, University of Michigan School of Public Health, Ann Arbor, MI, USA
In the result section, the second paragraph should read from the third sentence onwards as: For physical health, the highest odds of unemployment were observed for those with low education and poor health in early work (OR: 4.91; 95\% CI 3.68, 6.56) and mid-work life (OR: 5.10; 95\% CI 4.39, 5.93), respectively. However, the absolute risk of unemployment for those with low education and poor physical health was highest in late work life $(20.5 \%)$, followed by early work life $(15.5 \%)$ and mid-work life $(14.7 \%)$. Interaction between low education and poor physical health was observed in early (RERI: 1.66; 95\% CI $0.26,3.07$ ) and mid (RERI: 1.25 ; 95\% CI 0.56, 1.93) work life and extended to medium education in early (RERI: $0.80 ; 95 \%$ CI $0.16,1.44)$ and mid (RERI: 0.95; 95\% CI $0.49,1.42$ ) work life.

In the result section, the third paragraph should read as: For mental health, the highest odds of unemployment were observed for those with low education and poor health in early (OR: 5.80; 95\% CI 4.39, 7.66) and mid-work life (OR: 6.12; 95\% CI 5.21, 7.19). However, as was found for physical health, the absolute risk of unemployment for those with low education and poor mental health was highest in late work life $(19.5 \%)$, followed by early work life $(16.8 \%)$ and mid-work life $(16.3 \%)$. Interaction between low education and poor mental health was observed across all stages of the work life, with the interaction effect decreasing from a RERI of 2.13 (95\% CI 0.61 , $3.64)$ in early work life to 1.41 (95\% CI $0.61,2.20)$ and $0.58(95 \%$ CI $0.04,1.11)$ in mid- and late work life, respectively.

In the result section, the last sentence should read as: However, the general pattern of interaction effects was similar to the one observed in the main analysis.

In the discussion section, the first sentence of the second paragraph should read as: We found an interaction between low education and poor physical health on unemployment for participants in early and mid-work life.

In the discussion section, the third paragraph from the second to the second-last sentence should read as: 
Normally, the pool of healthy workers is much larger in early and mid- than in late work life (Niccoli 2012). Selection into unemployment, based on health, may thus be more likely for those in their early and mid-work life, especially when they have a low education. Sensitivity analyses did show a stronger interaction between low education and poor physical health in early work life than in the regular analyses.

In the discussion section, the second sentence of the last paragraph should read as: More importantly, low education and poor mental health may exacerbate each other's impact on unemployment across all work life stages, whereas low education and poor physical health may exacerbate each other's impact on unemployment in early and mid-work life.

Tables 1, 2, 3 and 4 should read as (corrected values are bold):

The Electronic Supplementary material is also updated.
Table 1 Baseline

characteristics of the study population by work life stage (The Netherlands, 2006-2013)

\begin{tabular}{llll}
\hline & Work life stage & & \\
\cline { 2 - 4 } & $\begin{array}{l}\text { Early }(25-34) \\
(n=13,479)\end{array}$ & $\begin{array}{l}\text { Mid }(35-49) \\
(n=39,879)\end{array}$ & $\begin{array}{l}\text { Late }(50-64) \\
(n=15,760)\end{array}$ \\
\hline Age [mean (SD)] & $29.9(2.8)$ & $42.8(4.2)$ & $54.6(4.1)$ \\
Female gender (\%) & 57.1 & 56.4 & 53.2 \\
Living in couple (\%) & 74.7 & 86.0 & 87.8 \\
Educational level (\%) & & & \\
High & 44.5 & 30.5 & 28.3 \\
Medium & 42.5 & 43.6 & 33.7 \\
Low & 13.0 & 25.8 & 38.0 \\
Unemployed (\%) & & & 11.6 \\
Dutch definition & 5.9 & 7.1 & 3.6 \\
International definition & 3.4 & 2.5 & $\mathbf{5 1 . 3}(\mathbf{7 . 3})$ \\
PCS [mean (SD)] & $\mathbf{5 3 . 3}(\mathbf{6 . 5})$ & $\mathbf{5 2 . 3}(\mathbf{7 . 1})$ & $\mathbf{2 9 . 5}$ \\
Poor PCS (\%) & $\mathbf{2 0 . 0}$ & $\mathbf{2 4 . 7}$ & $53.6(7.7)$ \\
MCS [mean (SD)] & $\mathbf{5 1 . 7 ( 8 . 2 )}$ & $52.5(8.2)$ & $\mathbf{2 0 . 3}$ \\
Poor MCS (\%) & $\mathbf{2 7 . 2}$ & 24.4 &
\end{tabular}

$S D$ standard deviation, $P C S$ physical component score, $M C S$ mental component score 


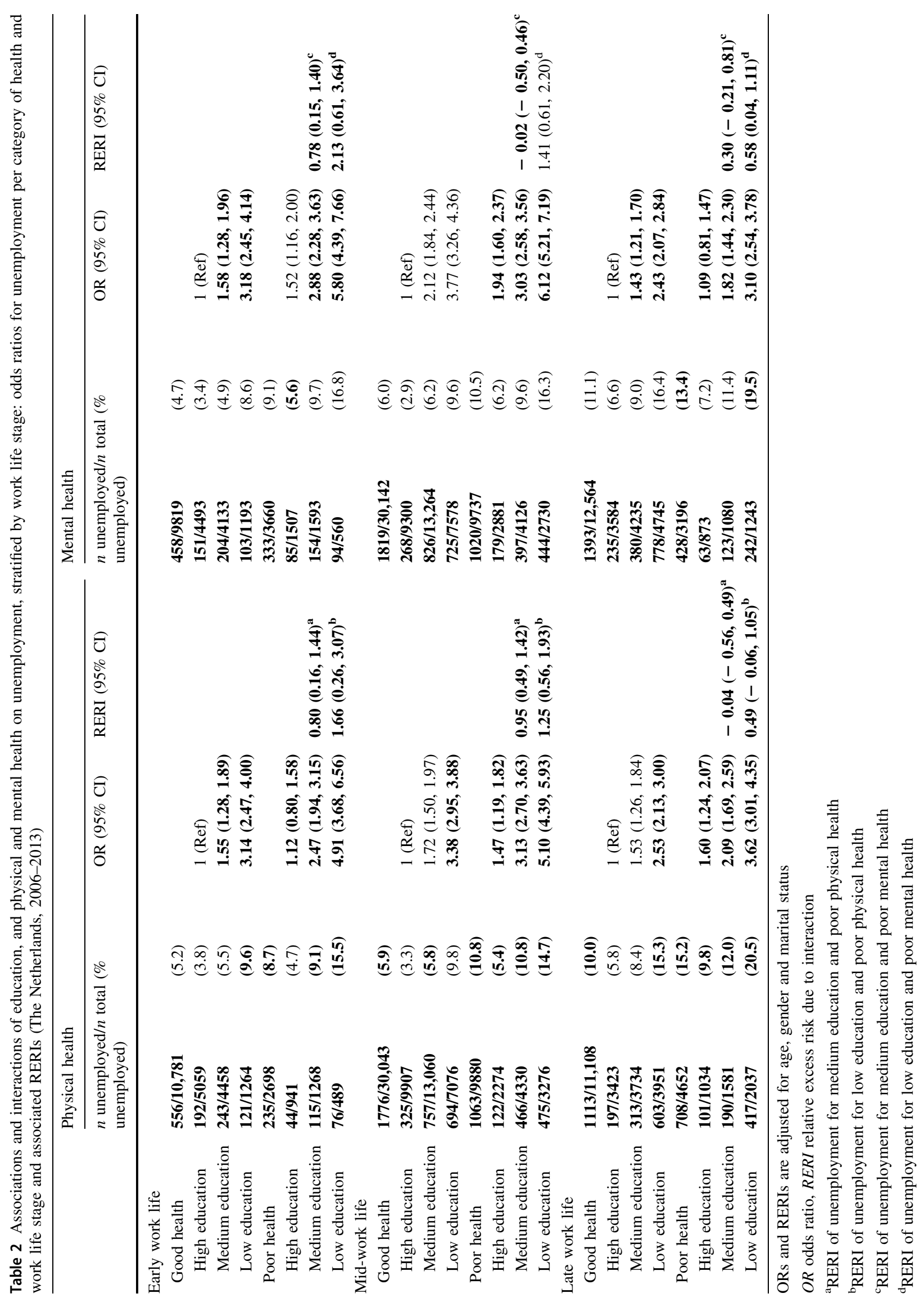


Table 3 Associations of education and unemployment within categories of physical and mental health, stratified by work life stage (The Netherlands, 2006-2013)

\begin{tabular}{|c|c|c|}
\hline & $\begin{array}{l}\text { Physical health } \\
\text { OR }(95 \% \text { CI })\end{array}$ & $\begin{array}{l}\text { Mental health } \\
\text { OR }(95 \% \text { CI })\end{array}$ \\
\hline \multicolumn{3}{|l|}{ Early work life } \\
\hline \multicolumn{3}{|l|}{ Good health } \\
\hline High education & 1 (Ref) & $1(\operatorname{Ref})$ \\
\hline Medium education & $1.56(1.28,1.89)$ & $1.60(1.29,1.99)$ \\
\hline Low education & $3.17(2.49,4.04)$ & $3.32(2.54,4.33)$ \\
\hline \multicolumn{3}{|l|}{ Poor health } \\
\hline High education & 1 (Ref) & 1 (Ref) \\
\hline Medium education & $2.19(1.53,3.14)$ & $1.86(1.41,2.45)$ \\
\hline Low education & $4.33(2.91,6.44)$ & $3.64(2.65,4.99)$ \\
\hline \multicolumn{3}{|l|}{ Mid-work life } \\
\hline \multicolumn{3}{|l|}{ Good health } \\
\hline High education & 1 (Ref) & 1 (Ref) \\
\hline Medium education & $1.71(1.49,1.95)$ & $2.10(1.82,2.42)$ \\
\hline Low education & $3.39(2.95,3.89)$ & $3.81(3.29,4.40)$ \\
\hline \multicolumn{3}{|l|}{ Poor health } \\
\hline High education & 1 (Ref) & 1 (Ref) \\
\hline Medium education & $2.13(1.73,2.63)$ & $1.57(1.30,1.88)$ \\
\hline Low education & $3.41(2.77,4.22)$ & $3.05(2.54,3.67)$ \\
\hline \multicolumn{3}{|l|}{ Late work life } \\
\hline \multicolumn{3}{|l|}{ Good health } \\
\hline High education & 1 (Ref) & 1 (Ref) \\
\hline Medium education & $1.53(1.27,1.85)$ & $1.44(1.21,1.72)$ \\
\hline Low education & $2.50(2.10,2.97)$ & $2.39(2.04,2.80)$ \\
\hline \multicolumn{3}{|l|}{ Poor health } \\
\hline High education & 1 (Ref) & 1 (Ref) \\
\hline Medium education & $1.30(1.00,1.68)$ & $1.63(1.18,2.25)$ \\
\hline Low education & $2.27(1.79,2.88)$ & $2.93(2.18,3.93)$ \\
\hline
\end{tabular}

ORs are adjusted for age, gender and marital status

Some categories in this table are similar to those in Table 2, but ORs may slightly differ because these are within category analysis (i.e., different size of the sample being analyzed and therefore a slightly different correction for age, gender and marital status)

$O R$ odds ratio
Table 4 Associations of physical, and mental, health and unemployment within categories of education, stratified by work life stage (The Netherlands, 2006-2013)

\begin{tabular}{|c|c|c|}
\hline & $\begin{array}{l}\text { Physical health } \\
\text { OR }(95 \% \text { CI) }\end{array}$ & $\begin{array}{l}\text { Mental health } \\
\text { OR (95\% CI) }\end{array}$ \\
\hline \multicolumn{3}{|l|}{ Early work life } \\
\hline \multicolumn{3}{|l|}{ High education } \\
\hline Good health & 1 (Ref) & 1 (Ref) \\
\hline Poor health & $1.20(0.85,1.68)$ & $1.59(1.20,2.09)$ \\
\hline \multicolumn{3}{|c|}{ Medium education } \\
\hline Good health & 1 (Ref) & 1 (Ref) \\
\hline Poor health & $1.57(1.25,2.00)$ & $1.79(1.44,2.24)$ \\
\hline \multicolumn{3}{|l|}{ Low education } \\
\hline Good health & 1 (Ref) & 1 (Ref) \\
\hline Poor health & $1.52(1.11,2.09)$ & $1.79(1.31,2.43)$ \\
\hline \multicolumn{3}{|l|}{ Mid-work life } \\
\hline \multicolumn{3}{|l|}{ High education } \\
\hline Good health & 1 (Ref) & 1 (Ref) \\
\hline Poor health & $1.50(1.21,1.86)$ & $2.02(1.65,2.45)$ \\
\hline \multicolumn{3}{|c|}{ Medium education } \\
\hline Good health & 1 (Ref) & 1 (Ref) \\
\hline Poor health & $1.83(1.62,2.07)$ & $1.43(1.26,1.63)$ \\
\hline \multicolumn{3}{|l|}{ Low education } \\
\hline Good health & 1 (Ref) & 1 (Ref) \\
\hline Poor health & $1.50(1.32,1.70)$ & $1.60(1.40,1.82)$ \\
\hline \multicolumn{3}{|l|}{ Late work life } \\
\hline \multicolumn{3}{|l|}{ High education } \\
\hline Good health & 1 (Ref) & 1 (Ref) \\
\hline Poor health & $1.66(1.28,2.15)$ & $1.15(0.85,1.54)$ \\
\hline \multicolumn{3}{|c|}{ Medium education } \\
\hline Good health & 1 (Ref) & $1(\operatorname{Ref})$ \\
\hline Poor health & $1.39(1.14,1.69)$ & $1.28(1.02,1.60)$ \\
\hline \multicolumn{3}{|l|}{ Low education } \\
\hline Good health & 1 (Ref) & 1 (Ref) \\
\hline Poor health & $1.43(1.24,1.66)$ & $1.26(1.06,1.49)$ \\
\hline
\end{tabular}

ORs are adjusted for age, gender and marital status

Some categories in this table are similar to those in Table 2, but ORs may slightly differ because these are within category analysis (i.e., different size of the sample being analyzed and therefore a slightly different correction for age, gender and marital status

$O R$ odds ratio 